\title{
Building up resilience of construction sector SMEs and their supply chains to extreme weather events
}

\author{
Gayan Wedawatta \\ School of the Built Environment, University of Salford \\ g.s.d.wedawatta@pgr.salford.ac.uk \\ Bingunath Ingirige \\ School of the Built Environment, University of Salford \\ m.j.b.ingirige@salford.ac.uk \\ Dilanthi Amaratunga \\ School of the Built Environment, University of Salford \\ r.d.g.amaratunga@salford.ac.uk \\ The University of Salford \\ School of the Built Environment \\ Maxwell Building \\ The Crescent \\ Salford \\ M5 4WT, UK
}




\begin{abstract}
Wider scientific community now accept that the threat of climate change as real and thus acknowledge the importance of implementing adaptation measures in a global context. In the UK, the physical effects of climate change are likely to be directly felt in the form of extreme weather events, which are predicted to escalate in number and severity in future under the changing climatic conditions. Construction industry; which consists of supply chains running across various other industries, economies and regions, will also be affected due to these events. Thus, it is important that the construction organisations are well prepared to withstand the effects of extreme weather events not only directly affecting their organisations but also affecting their supply chains which in turn might affect the organisation concerned. Given the fact that more than $99 \%$ of construction sector businesses are SMEs, the area can benefit significantly from policy making to improve SME resilience and coping capacity. This paper presents the literature review and synthesis of a doctoral research study undertaken to address the issue of extreme weather resilience of construction sector SMEs and their supply chains. The main contribution of the paper to both academia and practitioners is a synthesis model that conceptualises the factors that enhances resilience of SMEs and their supply chains against extreme weather events. This synthesis model forms the basis of a decision making framework that will enable SMEs to both reduce their vulnerability and enhance their coping capacity against extreme weather. The value of this paper is further extended by the overall research design that is set forth as the way forward.
\end{abstract}

Keywords:, Extreme weather events, Construction SMEs, Resilience, Supply chains, Vulnerability 


\section{Introduction}

Various stakeholders of a community are affected at varying magnitudes by EWEs. Small and Medium-scale Enterprises (SMEs), which form a significant portion of a community in many economies, are also affected by such events. The SMEs are often affected disproportionately by EWEs when compared with their larger counterparts (Tierney and Dahlhamer, 1996, Webb et al., 2000, Alesch et al., 2001). SMEs are, in fact, considered as the most vulnerable section of the UK economy to the impacts of extreme weather (Crichton, 2006). Their vulnerability arises virtually by definition because of the small scale of their human and financial resources (Bannock, 2005). SMEs, being highly vulnerable to the effects of EWEs, are required to be adequately prepared to face such events, in order to prevent, withstand and recover following such an event. Previous research reveals that small businesses are not adequately prepared to cope up with the risk of EWEs and other natural hazards and to recover following such an event (Tierney and Dahlhamer, 1996, Alesch et al., 2001, Yoshida and Deyle, 2005, Crichton, 2006, Dlugolecki, 2008).

SMEs may encounter unfavourable consequences, if they are affected by EWEs, due to their increased vulnerability and not being adequately prepared to deal with such an event. Moreover, SMEs suffer even without having been directly affected by an EWE, due to the vulnerability of the supply chain, utilities and transport infrastructure (Burnham, 2006). Indeed there is a view that the risks to the supply chain are one of the most important (Huddleston and Eggen, 2007). Improving the resilience of SMEs to the effects of EWEs has thus become an important issue, with the increasing threat of EWEs. Being resilient to EWEs is particularly important to businesses, due to the fact that they present businesses with positive consequences in addition to the negative consequences. Being resilient will allow businesses not only to minimize the threat of negative consequences, but also to benefit from the positive consequences presented by EWEs. As far as SMEs are concerned, being resilient might well decide the survival or the failure of an 
SME affected, creating economic and social consequences. While the loss of an individual SME may not cause a significant impact on the local economy in terms of the earnings it generates or the number of people it employs, the collective losses of a number of small businesses from a weather extreme may devastate a local economy (Yoshida and Deyle, 2005). Hence, improving the resilience of SMEs and their supply chains to EWEs has become an important issue given the ever increasing threat of such events.

This paper presents the initial literature review and synthesis of a doctoral research study undertaken to address the issue of resilience of construction sector SMEs and their supply chains to EWEs. It first presents the background to the research and research problem to be investigated. The paper then discuses the extant literature and presents a conceptual framework developed to characterise the research problem contextualised within its natural parameters. Paper concludes by stressing the need for further research in this area and setting out the way forward of the research.

\section{Background}

In the recent years the world has witnessed increases in the intensity and frequency of Extreme Weather Events (EWEs) (Beniston and Stephenson, 2004, Thibault and Brown, 2008). These EWEs have created significant economic and social costs to the communities around the world. There is wider speculation that this increased intensity and frequency of EWEs is primarily due to intensified climate change and that there is a strong link between the two (Stern, 2007). Increases in the number and severity of EWEs are expected in the future, due to the impacts of climate change (Environment Agency, 2005, Munich Re, 2007, Stern, 2007). Consequently, costs of EWEs are also expected to escalate in future and the Stern review (2007) reveals that the average annual costs of extreme weather could reach about $0.5-1 \%$ of world's GDP by the middle of the 21 st century. Thus, threat of EWEs has, and will become a prime challenge to be dealt with by communities around the world. The significant scale of the risk of EWEs has made it important for the 
communities to be able to adapt to the risk created by them and prepare for the disruptions caused by them (Helmer and Hilhorst, 2006). Resilience to EWEs has thus become an issue of significant importance to the communities around the world, with the UK being no exception, as the risk of weather extremes are also expected to increase in future in the UK .

As discussed above, resilience to EWEs is specifically important for the SME sector due to many factors. This is of particular importance to the construction industry, given the fact that SMEs account for the bulk portion of employment $(83.7 \%)$ and turnover generation (67.4\%) in the industry (BERR, 2008a). Hence, it is clear that the successful operation of SMEs is of significant importance to the successful operation of the construction sector as a whole. Further, the need for more resilient structures and the need for reconstruction after the effects of a physically damaging weather event place a particular importance on the construction industry in terms of weather extremes. As construction activities are normally carried out in an open environment, their activities are largely dependent on weather unlike some other industry sectors. Thus, EWE resilience is a matter of significant interest to the construction industry. As the construction industry is overwhelmingly comprised of SMEs, SME resilience to EWEs has become an important aspect presenting many research opportunities.

\section{Research problem}

As mentioned above, increased vulnerability to the effects of EWEs places SMEs at a higher risk when compared with their larger counterparts (Tierney and Dahlhamer, 1996, Webb et al., 2000, Alesch et al., 2001). As SME contribution is critical for the successful operation of local communities and economies, improving SME resilience against the effects of EWEs has become an issue which warrants considerable attention. Investigation of the business response to EWEs has long been neglected when compared with studies on the residential sector (Tierney and Dahlhamer, 1996, Tierney, 1997, Webb et al., 2002), and only a very few studies have 
looked at SME response to EWEs specifically. There seems to be an obvious gap between the increased need of improving SME resilience to EWEs and the current knowledge with regard to this issue.

As SMEs constitute more than $99 \%$ of businesses in the construction industry and as they generate more than half of the employment and turnover, SME participation is critical for the successful operation of the construction industry. Given that many large construction projects involve a large number of SME participants, delivery of a successful project is dependent upon the involvement of these SMEs. Government studies into the construction industry (Latham, 1994, Egan, 1998), have in fact, identified that the integration of the whole supply chain as a critical factor in improving effectiveness in the construction industry. EWEs are capable of creating disruptions to the activities of construction sector, not only via their direct physical effects but also via disruptions to the supply chain of the industry. As the risk of EWEs is increasing, there is a growing need for preparing the construction sector SMEs and their supply chain partners to face the challenges created by EWEs. Further, EWEs also present businesses with positive consequences as well (Heliview Research, 2008, Norrington and Underwood, 2008, Metcalf et al., 2009). It is important that SMEs are prepared not only to minimise the negative consequences, but also, to exploit the positive consequences presented by EWEs. However, not many studies have been undertaken to study how the construction organisations have managed EWEs before. The research is developed to address this gap in the knowledge, identifying the growing need for improving the resilience of construction sector SMEs and their supply chain to the effects of EWEs.

As mentioned above, previous research has identified the need for enhancing the capacity for resilience of SMEs. Improving the decision making of SMEs is a key element in improving their resilience (Wedawatta et al., 2010). However, Berkhout (2004) reported that businesses found it difficult to relate climate change and EWE's to the risk models that they currently use. Norrington and 
Underwood (2008) identified the need for a toolkit which will enable SMEs to make better business decisions with regard to climate related risks specific to their business, in their study of how the directors of SMEs are responding to the risk of climate change and weather extremes. The research aims to address this requirement by developing a decision making framework that can be used by construction SMEs to improve their resilience against EWEs. Based on this overarching research problem, this paper addresses issues related to resilience of construction SMEs and aims to provide a synthesis framework to capture the issues being discussed.

For the purpose of the research study in which this doctoral research is a part of, EWEs are defined as "meteorological conditions that are rare for a particular place and/or time". Although the word "rare" is used here, the term incorporates "weather of sufficient severity to generate a hazard". This definition is similar to the definitions put forward by Francis and Hengeveld (1998), and Intergovernmental Panel on Climate Change - IPCC (2007). The definition goes forward to identify that "rarity" can change over time. Heavy rainfall, heavy snowfall, extreme temperatures (both high and low), storms as well as flooding and heat waves are some of the examples for EWEs. The term incorporates both "extreme weather conditions" like heavy rainfall and extreme temperatures as well as "extreme weather hazards" like flooding, which could occur due to one or more of extreme weather conditions (e.g. heavy rainfall, heavy snowfall) coupled with other sources (e.g. inadequate/ blocked drainage).

As the aim of the research is to develop a decision making framework that can be used by construction SMEs to enhance their resilience to EWEs in general, the scope of the research will not be limited to any specific EWEs at the moment. As Linnenluecke and Griffiths (2010) point out, businesses have to go through a learning curve, which will enable them to learn from unique weather extremes that would improve their resilience to a future weather extreme. This research adopts their view and considers a range of EWEs that impact SMEs and their supply chains on a global scale. Further, the 
scope of the research will narrow down into the unique behaviour entailed within SMEs in the construction industry.

\section{Literature review}

\subsection{SMEs in construction}

The construction sector is a major component in any economy. In the $\mathrm{UK}$, its output is worth over $£ 100$ billion a year, accounts for $8 \%$ of Gross Domestic Product (GDP) and provides employment for around 3 million workers (BERR, 2008b). The UK construction industry constitutes about $21 \%$ of the total enterprises in the UK (BERR, 2008a). Hence, the construction industry makes an important contribution to the competitiveness and prosperity of the economy (BERR, 2008b). The construction industry is not only a critical component of the nation's economy, it is also a fundamental factor in the quality of people's lives and the ability of the government to achieve many of its policy aims (Bosher et al., 2007a). Over 99\% of private sector businesses operating in UK construction sector fall to the category of SMEs (BERR, 2008a).

In the UK economy, $83.8 \%$ of employment in construction sector is provided by SMEs and $67.4 \%$ of turnover is generated by them (BERR, 2008a). These statistics depicts the significance of SMEs in the UK construction sector and their significant contribution to the national economy. A majority of these SMEs are sole proprietors or partnerships comprising only the self-employed owner-manager, or companies comprising only an employee director and hence fall to the category of micro businesses (BERR, 2008a). Whilst the bulk portion of the remaining is small businesses, only a smaller portion are medium-sized. Due to the presence of many SMEs and less large businesses, a supply chain consisting of hundreds of organisations tend to deliver major construction projects (Stewart et al., 2004). In the construction sector, the network of supply chain members can often be extremely complex, particularly on larger projects where the number of separate supplying organisations will run into hundreds, if not thousands (Briscoe et al., 2001). Citing a number of sources, 
Sexton and Barrett (2003) avow that the industry is generally driven by single and unique projects, each creating and disbanding project teams made up of varying combinations of large and small firms from across the supply chain spectrum. Thus, effective management and relationship of the entire supply chain is required to achieve best value in construction industry.

\subsection{Extreme weather events and construction SMEs}

Extreme weather can create a variety of effects on construction sector SMEs including direct effects such as disruption to site works and indirect effects due to disruptions to deliveries and utility supplies (Metcalf et al., 2009). Such effects may well lead to the ultimate failure of businesses, especially SMEs. For example, it was predicted by the Centre for Economics and Business Research Ltd (CEBR) that there will be around 2000 - 3000 additional business failures in the UK due to the disruptions caused by the heavy winter snowfall in 2009, and that many of these businesses would be from the construction and retail sectors (McWilliams, 2009). However, EWEs may well present construction SMEs with positive consequences / business opportunities as well, in addition to negative consequences. These may include increased demand for adaptation in buildings, maintenance, post event reconstruction, and also possible new products and techniques (e.g. new flood protection systems). Although demand for reconstruction following natural hazards and disasters can be beneficial for construction SMEs, excessive demand can be detrimental as well. For instance, Ingirige et al (2008) discuss how the excessive demand for reconstruction in Sri Lanka following the South Asian tsunami in 2004 fuelled inflationary price increases within the whole industry. Such excessive demand may affect construction companies, especially the SMEs, negatively as well. Being a resilient business will not only allow construction SMEs to prevent, withstand, recover and learn from EWEs (i.e. minimise negative consequences), but also to utilise the opportunities arising from them (i.e. maximise positive consequences). 
More importantly, in addition to the business impact of EWEs on SMEs, the role of construction SMEs in achieving community resilience to EWEs, other natural hazards, and disasters in general is significant. Chang et al (2010) highlight the importance of the role of construction industry in disaster management and post disaster reconstruction. Haigh and Amaratunga (2010) discuss the importance of the role of disciplines associated with the built environment in improving societal resilience to disasters at each stage of the disaster management process and for all key primary functions; namely perception, analysis, communication and information. Furthermore, Bosher et al (2007b) conclude that the disciplines associated with the construction sector have to be more involved with disaster risk management initiatives in the UK. Inevitably, this would mean more involvement of construction SMEs, as they represent a significant portion of the industry. Thus, it can be identified that the resilience of construction SMEs against EWEs has wider societal importance as well in addition to the importance to the construction industry and the SMEs themselves.

\subsection{Extreme weather events and supply chains}

\subsubsection{Vulnerability of supply chains}

Supply chains face disruptions of various sorts (Snyder et al., 2006) and such disruptions are a common phenomenon (Svensson, 2000). Natural disasters, industrial disputes, terrorism (Christopher and Peck, 2004), dependence on a single supplier, supplier bankruptcy, war, and political instability (Wilson, 2007) have all resulted in serious disruptions to supply chain activities. Recent events such as the fuel protests in 2000, foot and mouth disease in 2001 (Peck, 2005 ) and the hot summer in the UK in 2003, hurricanes Katrina and Rita (Snyder et al., 2006), September 11 terror attack (Sheffi and Rice, 2005) in the USA etc, have demonstrated that a disruption affecting an entity anywhere in the supply chain can have a direct effect on a businesses' ability to continue operations, get finished goods to market or provide critical services to customers (Jüttner et al., 2003). Snyder and Shen (2006) declare that supply chain 
disruptions can have significant costs (e.g. damage to facilities, inventory, electronic networks, and infrastructure) and subsequent losses due to downtime. Inventory costs due to obsolescence, markdowns and stock-outs can be significant (Christopher and Lee, 2004). Moreover, a company that experiences a supply chain disruption can expect to face significant declines in sales growth, stock returns, shareholder wealth, and customer goodwill (Snyder and Shen, 2006). Therefore, it is critical to account for disruptions during the design of supply chain networks so that they perform well even after a disruption (Snyder et al., 2006).

\subsubsection{EWEs and supply chains}

Extreme weather events such as floods, hurricanes, storms etc can have significant effects on supply chains (Christopher and Peck, 2004, Kleindorfer and Saad, 2005). As mentioned earlier, vulnerability of supply chain to EWEs is capable of creating significant business impacts, even without the business concerned being directly affected by the event. Indeed, there is a view that the risks to the supply chain are some of the most important (Huddleston and Eggen, 2007), especially due to the widespread nature of modern supply chains which run across different industries and economies. Table 1 shows the effects experienced by UK businesses which were affected by floods in year 2007. Many of the major effects experienced are related to supply chain of those businesses, and thus provides evidence for the argument that risk to the supply chain are significantly important.

Table 1 - Effects of flooding on businesses

\begin{tabular}{|ll|}
\hline Effect & $\begin{array}{l}\text { \% of Businesses } \\
\text { Affected }\end{array}$ \\
\hline Staff unavailable for work & $53 \%$ \\
\hline Premises flooded (offices, shops, etc) & $38 \%$ \\
\hline Suppliers disrupted & $27 \%$ \\
\hline Increase in trade/demand for services & $24 \%$ \\
\hline Loss of power & $18 \%$ \\
\hline
\end{tabular}




\begin{tabular}{ll|}
\hline Loss of water supplies & $11 \%$ \\
\hline
\end{tabular}

(Source: Woodman, 2008)

Businesses may suffer without being directly affect by an EWE, due to the vulnerability of supply chain, utilities and transport infrastructure (Burnham, 2006). If the supply chain of a particular business is affected by an EWE which occurred elsewhere, it may affect the performance of the business, even without the particular business being directly affected by the actual physical EWE. It is therefore necessary for business organizations to consider the wider impacts of EWEs that can affect their businesses and their supply chains, not only the direct physical impacts.

Summarising its experience of working with SMEs with regard to climate change and EWEs, the UKCIP identify that "key risks often related to markets and supply chains" for SMEs (UKCIP, 2009). This issue is one of the six key issues identified by the UKCIP with regard to climate change adaptation of SMEs. The importance of supply chain effects of EWEs were also highlighted in a workshop session (organised by the London Climate Change Partnership) facilitated by "Community Resilience to Extreme Weather - CREW" researchers; of which this doctoral research forms a part, by the representatives of SMEs and support organisations for SMEs. Furthermore, the need to have coping mechanisms to deal with the supply chain disruptions was also highlighted by the SME representatives as it is often difficult for SMEs to control its supply chain due to their limited scale of operations. The other key issues raised were the need for specific and simple business advice, continuous help in implementation, enhanced awareness and a medium to discuss the supply chain related issues.

\section{Resilience to EWEs}

For the purpose of this research, the working terminology developed for the CREW research project will be used. Here, resilience is defined as "the ability to prevent, withstand, recover from and learn from the impacts of extreme weather". The definition resembles the 
definitions put forward by Intergovernmental Panel on Climate Change (2007) and International Strategy for Disaster Reduction ISDR (2009). Different researchers have come up different definitions for resilience as well as what constitutes / contributes to resilience. Table 2 captures some of the frameworks developed by researchers to represent resilience addressing different perspectives.

Table 2 - Frameworks on Resilience from a hazard perspective

\begin{tabular}{|c|c|c|c|}
\hline Source & Context & Focusing on & Components of resilience \\
\hline $\begin{array}{l}\text { Bruneau et } \\
\text { al. (2003) } \\
\text { Tierney and } \\
\text { Bruneau } \\
\text { (2007) }\end{array}$ & $\begin{array}{l}\text { Seismic, } \\
\text { Disasters }\end{array}$ & $\begin{array}{l}\text { Communities, } \\
\text { Infrastructure } \\
\text { systems }\end{array}$ & $\begin{array}{l}\text { Robustness } \\
\text { Redundancy } \\
\text { Resourcefulness } \\
\text { Rapidity }\end{array}$ \\
\hline $\begin{array}{l}\text { Paton } \\
(2007)\end{array}$ & $\begin{array}{l}\text { Natural } \\
\text { hazards }\end{array}$ & $\begin{array}{l}\text { Societal } \\
\text { resilience }\end{array}$ & 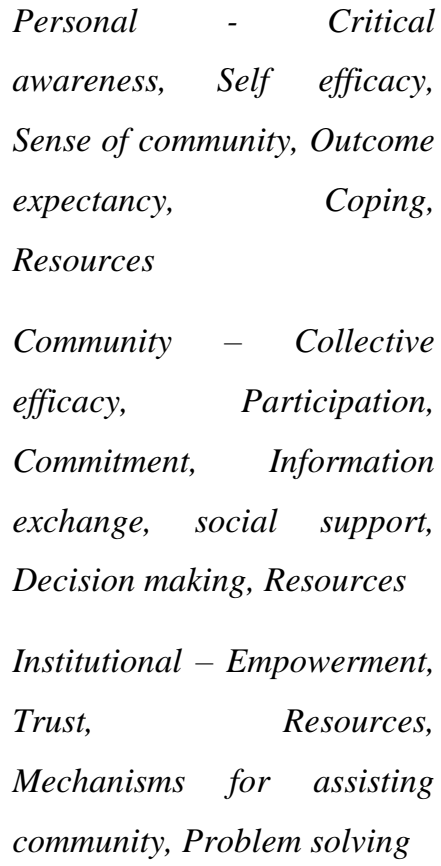 \\
\hline $\begin{array}{l}\text { McManus et } \\
\text { al. (2007) }\end{array}$ & Disasters & $\begin{array}{l}\text { Organisational } \\
\text { resilience }\end{array}$ & $\begin{array}{l}\text { Situation awareness - Roles } \\
\text { and responsibilities, } \\
\text { Understanding of hazards } \\
\text { and consequences, } \\
\text { Connectivity awareness, } \\
\text { Insurancerareness, } \\
\text { Recovery priorities }\end{array}$ \\
\hline & & & Management of keystone \\
\hline
\end{tabular}






Paton's (2007) model of resilience addresses societal resilience to natural hazards from a multi-level perspective. Variables affecting societal resilience are identified at three levels; personal, community and institutional. Variables identified here provide insights in to components of resilience from a business perspective as well. Disaster Resilience of Place (DROP) model of Cutter et al (2008) represents community resilience to natural disasters. This framework too has identified a range of resilience indicators and is suggested to be used for comparative assessments of disaster resilience at the local or community level. Although organisational resilience is not addressed directly in these frameworks, a significant input can be obtained from them in developing a framework for SME resilience to EWEs. For instance, DROP model identifies resilience and vulnerability as neither totally mutually exclusive nor totally mutually inclusive but overlap each other and how coping responses and absorptive capacity affect the resilience. 
McManus et al (2007) identify resilience, in an organisational context, "as a function of an organisation's situation awareness, management of keystone vulnerabilities, and adaptive capacity in a complex, dynamic and interconnected environment". They have developed a framework to assess and analyse organisational resilience involving 15 key resilience indicators which represent key resilience issues in an organisation. These indicators are grouped under three main interrelated categories; situation awareness, management of keystone vulnerabilities, and adaptive capacity. Although this framework is perhaps one of the most comprehensive frameworks in terms of organisational resilience, it has to be investigated as to what extent some of the indicators are applicable to SMEs.

\section{Conceptual framework}

In this research, resilience is seen as a accumulation of vulnerability, coping capacity and coping strategies, in an organisational context. It is thought that the coping capacity of a certain SME and the presence or absence of coping strategies coupled with its vulnerability will determine what level of resilience it can achieve against EWE impacts. Therefore, reducing vulnerability, improving coping capacity and implementing coping strategies are seen as the elements of improving the resilience of SMEs. These three factors are interrelated and not mutually exclusive. The decision making framework to be developed will be focused around these three key issues of concern. They address the elements of preventing, withstanding and recovering from EWEs whereas the feedback from the level of resilience achieved will address the learn element in the definition. The conceptual framework developed has been influenced by existing frameworks on resilience such as the ones put forward by McManus et al (2007) and Cutter et al (2008). 




Figure 1 - Conceptual framework of the research

In Figure 1, vulnerability is defined as "the characteristics and circumstances of humans and human systems that determine how susceptible they are to the impact of EWEs". In a SME context, in broad terms, it relates to the extent to which a particular SME is susceptible to disruptions by EWEs. For instance from a construction SME context, having construction projects in high flood risk areas and conducting earth works during the winter period can be cited. Coping capacity, in this research, is defined as "the ability of people or organisations to limit adverse consequences of EWEs, using available resources and capabilities". For instance, these will involve identification of roles and responsibilities of employees in the event of an EWE and educating employees about the risks of EWEs. Coping strategies are defined as "actions that increase the ability to prevent, tolerate and/or recover from impacts" in this research. These may include both physical and non-physical actions such as obtaining business interruption insurance, business continuity planning, flood defences etc. The doctoral research aims to develop this conceptual framework further and come up with a practical decision making framework to be used by construction SMEs to enhance their resilience to EWEs. The framework will encompass approaches to assessing business vulnerability to EWE's, identification of coping strategies and measures leading to coping capacity, and study the impact of such measures on resilience. 


\section{The way forward}

The background to this research and the research problem to be investigated identified the importance of further study on the issue at hand and sets the scene for this research. The need for a tool to be used by SMEs enabling them to make better business decisions with regard to EWEs, considering the characteristics pertaining to SMEs, is thereby highlighted. The conceptual framework developed will be further expanded and validated following the empirical research.

A mixed method research approach will be used here to investigate the construction SMEs and develop the decision making framework. Creswell (2003) identified mixed method approach as "one in which the researcher tends to base knowledge claims on pragmatic grounds", and in which the researcher uses both the quantitative and qualitative data to best understand the research problems being investigated. Such an approach will provide a better account of the issues being investigated and achieving the aim and objectives of the research. Curran and Blackburn (2001) identified that mixed method approaches as common in small business research and as capable of deriving benefits from triangulation and characteristics inherent to both quantitative and qualitative approaches. Such an approach will also answer the call for triangulation and methodological pluralism in construction management research (Love et al., 2002, Dainty, 2008). As it is not intended here to discuss the research design in detail, Figure 2 captures the design of the doctoral research study in short. 


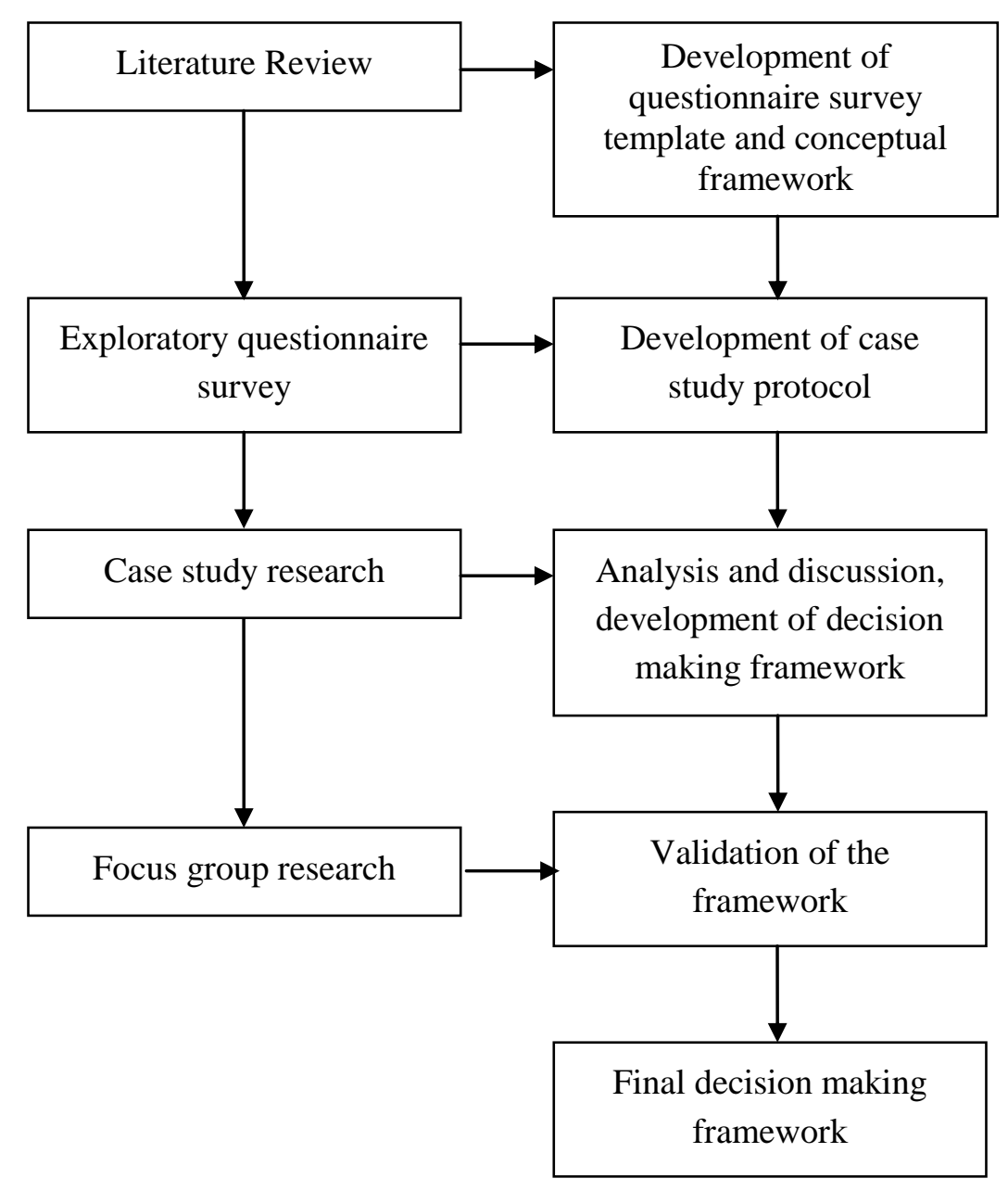

Figure 2 - Research design

\section{Conclusion}

SMEs are increasingly affected by EWEs leading to significantly negative as well as positive organisational consequences. This has necessitated the improvement of their resilience to such events, not only to minimise the negative consequences, but also to be able to effectively utilise the positive consequences. Improving the resilience of SMEs to EWEs requires a much broader view than a microscopic consideration of a single SME. The consideration should extend into the supply chains in which a particular SME is a part of. This is of specific importance to a sector like construction, in which the SMEs and their extended supply chain play a major role and are highly vulnerable to EWEs. Although these issues presents many research opportunities, scant literature available addressing these issues 
portrays the lack of academic attention and the need for more focused studies in this respect. There is thus an obvious incentive to focus on research related to resilience of construction SMEs and their supply chains to EWEs. Improving the resilience of SMEs is not only about implementing various coping strategies but also includes ways and means of reducing the vulnerability to such events.

Despite the significant threat of EWEs and the possibility of further increases in the future, even the recent studies suggest that SMEs are less proactive in being prepared to face the threat of EWEs and other natural hazards. This raises the important issue and challenge of integrating the good practices into the mainstream of SME activities in verge of ever increasing extreme weather conditions. The paper proposes vulnerability, coping capacity and coping strategies as inherent components of resilience to weather extremes from a business perspective. The conceptual framework emerged from the literature review and synthesis includes these components and will be expanded to develop a decision making framework embracing them. From a policy making perspective, the paper contributes towards contextualising the unique SME behaviour when faced with EWEs. Policy makers, therefore, must broaden the scope of their actions to include SMEs and the extended body of supply chain members, who are key components in the decision making process.

The effect of the supply chain also has a bearing on the research approach adopted in the study. Complex and wide spread nature of modern supply chains mean that businesses can be disrupted by weather extremes even without having a direct physical impact from such events. Therefore, it is important that SMEs prepare for such indirect impacts as well, not only the direct physical impacts of weather extremes. The conceptual framework developed embraces this issue and will be further investigated during the next stages of the research as depicted in the research design in Figure 2. 


\section{Acknowledgement}

The content of this paper forms part of a multi-disciplinary project into Community Resilience and Extreme Weather Events (CREW) being funded by the UK Engineering and Physical Sciences Research Council (EPSRC). The authors would like to acknowledge the contributions made by academics of partner universities for the general discussions that formed the background to this paper.

\section{References}

Alesch, D. J., Holly, J. N., Mittler, E. \& Nagy, R. (2001) Organizations at Risk: What happens when small businesses and not-for-profits encounter natural disasters. Small Organizations Natural Hazards Project, First Year Technical Report, University of Wisconsin-Green Bay. Fairfax, Public Entity Risk Institute.

Bannock, G. (2005) The Economics and Management of Small Business: An International Perspective. London. Taylor \& Francis Routledge.

Beniston, M. \& Stephenson, D. B. (2004) Extreme climatic events and their evolution under changing climatic conditions. Global and Planetary Change, 44, 1-9.

Berkhout, F., Hertin, J., Arnell, N. (2004) Business and Climate Change: Measuring and Enhancing Adaptive Capacity. Tyndall Centre Technical Report 11. Oxford, Tyndall Centre for Climate Change Research.

BERR (2008a) SME Statistics for the UK and Regions 2007. Enterprise Directorate Analytical Unit, Department for Business Enterprise and Regulatory Reform (BERR).

BERR (2008b) Strategy for sustainable construction. London, Department for Business, Enterprise \& Regulatory Reform: Construction Sector Unit.

Bosher, L., Carrillo, P., Dainty, A., Glass, J. \& Price, A. (2007a) Realising a resilient and sustainable built environment: towards a strategic agenda for the United Kingdom. Disasters, 31, 236-255.

Bosher, L., Dainty, A., Carrillo, P., Glass, J. \& Price, A. (2007b) Integrating disaster risk management into construction: a UK perspective. Building Research \& Information, 35, 163 - 177.

Briscoe, G., Dainty, A. R. J. \& Millett, S. (2001) Construction supply chain partnerships: skills, knowledge and attitudinal requirements. European Journal of Purchasing \& Supply Management, 7, 243-255.

Bruneau, M., Chang, S. E., Eguchi, R. T., Lee, G. C., O’Rourke, T. D., Reinhorn, A. M., Shinozuka, M., Tierney, K., A.Wallace, W. \& vonWinterfeldt, D. (2003) A Framework to Quantitatively Assess and Enhance the Seismic Resilience of Communities. Earthquake Spectra, 19, 733-752. 
Burnham, C. (2006) A Guide to Climate Change for Small- to Medium-sized Enterprises. IN HOLMES, R. (Ed.). Ontario, The Canadian Chamber of Commerce and Pollution Probe.

Chang, Y., Wilkinson, S., Seville, E. \& Potangaroa, R. (2010) Resourcing for a resilient post-disaster reconstruction environment. International Journal of Disaster Resilience in the Built Environment, 1, 65-83.

Christopher, M. \& Lee, H. (2004) Mitigating supply chain risk through improved confidence. International Journal of Physical Distribution \& Logistics Management, 34, 388-396.

Christopher, M. \& Peck, H. (2004) Building the Resilient Supply Chain. International Journal of Logistics Management, 15, $1-14$.

Creswell, J. W. (2003) Research design: Qualitative, quantitative, mixed methods approaches, London, SAGE Publications.

Crichton, D. (2006) Climate Change and its effects on Small Businesses in the UK, London, AXA Insurance UK.

Curran, J. \& Blackburn, R. A. (2001) Researching the small enterprise, London, SAGE Publications.

Cutter, S. L., Barnes, L., Berry, M., Burton, C., Evans, E., Tate, E. \& Webb, J. (2008) A place-based model for understanding community resilience to natural disasters. Global Environmental Change, 18, 598-606.

Dainty, A. R. J. (2008) Methodological pluralism in construction management research. IN KNIGHT, A. \& RUDDOCK, L. (Eds.) Advanced Research Methods in the Built Environment. Chichester, Wiley-Blackwell.

Dlugolecki, A. (2008) Climate Change and the Insurance Sector. The Geneva Papers, 33, 71-90.

Egan, J. (1998) Rethinking Construction. The report of the Construction Task Force to the Deputy Prime Minister, John Prescott, on the scope for improving the quality and efficiency of UK construction. London, Department of Trade and Industry.

Environment Agency (2005) The climate is changing: Time to get ready, Bristol, Environment Agency.

Francis, D. \& Hengeveld, H. (1998) Extreme Weather and Climate Change. Ontario, Environment Canada.

Haigh, R. P. \& Amaratunga, D. (2010) An integrative review of the built environment discipline's role in the development of society's resilience to disasters. International Journal of Disaster Resilience in the Built Environment, 1, 11-24.

Heliview Research (2008) Climate change effects, Breda, Heliview Research.

Helmer, M. \& Hilhorst, D. (2006) Natural disasters and climate change Disasters, 30, 1-4.

Huddleston, M. \& Eggen, B. (2007) Climate change adaptation for UK businesses: A report for the CBI task group on climate change Devon, Met Office.

Ingirige, B., Haigh, R. P., Malalgoda, C. \& Palliyaguru, R. (2008) Exploring good practice knowledge transfer related to post tsunami housing (re-)construction in Sri Lanka. Journal of Construction in Developing Countries, 13, 21-42.

IPCC (2007) Climate Change 2007: Impacts, Adaptation and Vulnerability. Contribution of Working Group II to the Fourth Assessment Report of the Intergovernmental Panel on Climate Change. IN PARRY, M. L., CANZIANI, O. F., PALUTIKOF, J. P., LINDEN, P. J. V. D. \& HANSON, C. E. 
(Eds.). Cambridge, Intergovernmental Panel on Climate Change.

Jüttner, U., Peck, H. \& Christopher, M. (2003) Supply chain risk management: outlining an agenda for future research. International Journal of Logistics Research and Applications, 6, 197-210.

Kleindorfer, P. R. \& Saad, G. H. (2005) Managing Disruption Risks in Supply Chains. Production \& Operations Management, 14, 53-68.

Latham, M. (1994) Constructing the Team. Final Report of the Government / Industry Review of Procurement and Contractual Arrangements In The UK Construction Industry. London, HMSO.

Linnenluecke, M. \& Griffiths, A. (2010) Beyond Adaptation: Resilience for Business in Light of Climate Change and Weather Extremes. Business \& Society, 49, 477-511.

Love, P. E. D., Holt, G. D. \& Li, H. (2002) Triangulation in construction management research. Engineering Construction and Architectural Management, 9, 294-303.

McManus, S., Seville, E., Brunsdon, D. \& Vargo, J. (2007) Resilience Management: A framework for assessing and Improving the resilience of organisations Resilient Organisations Research Report 2007/01 New Zealand, Resilient Organisations.

McWilliams, D. (2009) Hit from the big freeze will be 2-3 thousand businesses going bust earlier. London, Centre for Economics and Business Research Ltd, http://www.cebr.com/Resources/CEBR/The_cost_of_the_big freeze.pdf, Accessed on 18/09/09.

Metcalf, G., Jenkinson, K. \& Johnstone, K. (2009) A changing climate for business. Oxford, UK Climate Impacts Programme.

Munich Re (2007) Press release - 22 October 2007. München, Munich Re.

Norrington, H. \& Underwood, K. (2008) Climate change and small businesses: How directors are responding to the challenges of climate change - Research Findings 2008, Guildford, Climate South East.

Paton, D. (2007) Measuring and monitoring resilience in Auckland. GNS Science Report 2007/18. Institute of Geological and Nuclear Sciences Limited.

Peck, H. (2005) Drivers of supply chain vulnerability: an integrated framework. International Journal of Physical Distribution \& Logistics Management, 35, 210-232.

Sexton, M. \& Barrett, P. (2003) A literature synthesis of innovation in small construction firms: insights, ambiguities and questions. Construction Management and Economics, 21, 613-622.

Sheffi, Y. \& Rice, J. B. (2005) A supply chain view of the resillient enterprise. MIT Sloan Management Review, 47, 41-48.

Snyder, L. V., Scaparra, M. P. \& Daskin, M. S. (2006) Planning for Disruptions in Supply Chain Networks. IN GREENBERG, H. (Ed.) Tutorials in Operations Research. Baltimore, INFORMS.

Snyder, L. V. \& Shen, Z. M. (2006) Managing Disruptions to Supply Chains. The Bridge, 36, 39-45.

Stern, N. (2007) The Economics of Climate Change: The Stern Review, Cambridge, Cambridge University Press. 
Stewart, R. A., Mohamed, S. A. M. \& Marosszeky, M. (2004) An empirical investigation into the link between information technology implementation barriers and coping strategies in the Australian construction industry. Construction Innovation: information, process, management, 4, 155-171.

Svensson, G. (2000) A conceptual framework for the analysis of vulnerability of supply chains International Journal of Physical Distribution and Logistics Management, 30, 731749.

Thibault, K. M. \& Brown, J. H. (2008) Impact of an extreme climatic event on community assembly. Proceedings of the National Academy of Sciences, 105, 3410-3415.

Tierney, K. J. (1997) Business Impacts of the Northridge Earthquake. Journal of Contingencies and Crisis Management, 5, 87-97.

Tierney, K. J. \& Bruneau, M. (2007) Conceptualizing and Measuring Resilience: A Key to Disaster Loss Reduction. Transportation Research News. Washington, Transportation Research Board, National Research Council.

Tierney, K. J. \& Dahlhamer, J. M. (1996) Business Disruption, Preparedness And Recovery: Lessons From The Northridge Earthquake. DRC Preliminary Papers, Disaster Research Center, University of Delaware.

UKCIP (2009) Supporting SMEs - Key messages for awareness raising CLARA - Climate Adaptation Resource for Advisors. Oxford, UKCIP.

UNISDR (2009) UNISDR Terminology on Disaster Risk Reduction

Webb, G. R., Tierney, K. J. \& Dahlhamer, J. M. (2000) Business and Disasters: Empirical Patterns and Unanswered Questions. Natural Hazards Review, 1, 83-90.

Webb, G. R., Tierney, K. J. \& Dahlhamer, J. M. (2002) Predicting long-term business recovery from disaster: a comparison of the Loma Prieta earthquake and Hurricane Andrew. Global Environmental Change Part B: Environmental Hazards, 4, 45-58.

Wedawatta, G., Ingirige, B. \& Jones, K. (2010) Coping strategies against extreme weather events: A survey of SMEs in the UK. RICS COBRA research conference 2010 Université Paris-Dauphine, Paris.

Wilson, M. C. (2007) The impact of transportation disruptions on supply chain performance. Transportation Research Part E: Logistics and Transportation Review, 43, 295-320.

Yoshida, K. \& Deyle, R. E. (2005) Determinants of Small Business Hazard Mitigation. Natural Hazards Review, 6, 1-12. 